Special Issue on Recent Advances in Engineering Systems

\title{
Development of an automated vehicle stop system for cardiac emergencies
}

Tung T. Nguyen ${ }^{1}$, Issey Takahashi², Takahiro Tanaka ${ }^{2}$, Eijiro Takeuchi ${ }^{3}$, Shinpei Kato ${ }^{2,4}$, Tatsuya Suzuki ${ }^{1}$, Hitoshi Kanamori ${ }^{2}$, Yoshiki Ninomiya ${ }^{2}$, Hirofumi Aoki ${ }^{*}$

${ }^{1}$ Graduate School of Engineering, Nagoya University, Nagoya, Japan

${ }^{2}$ Institute of Innovation for Future Society, Nagoya University, Nagoya, Japan

${ }^{3}$ Gradute School of Information Science, Nagoya University, Nagoya, Japan

${ }^{4}$ Graduate School of Information Science and Technology, University of Tokyo, Japan

A R T I C L E IN F O

Article history:

Received: 05 April, 2017

Accepted: 12 May, 2017

Online: 05 June, 2017

Keywords:

Vehicle safety

Cardiac emergency

Automated driving

Bio-signal

\section{Introduction}

The association of driving and physical disorder has been researched for many years. Driving requires both physical and cognitive functions. Beside the effects of long time driving and many cognition stressors, deterioration of driving performance by physical disorder increases the risk of accidents [1]. Although multiple technologies such as adaptive cruise control and emergency braking embedded in the vehicle have decreased the stress of driving on the driver, the number of intrinsic sudden death in traffic accident is still high over the years (Table 1).

Table 1. Autopsy report of intrinsic sudden death of driver

\begin{tabular}{|c|c|c|c|c|}
\hline \multirow[t]{2}{*}{ Author } & \multirow[t]{2}{*}{ Location } & \multirow[t]{2}{*}{ Period } & \multicolumn{2}{|c|}{$\begin{array}{l}\text { Driver reported as intrinsic } \\
\text { sudden death }\end{array}$} \\
\hline & & & Number & Percentage \\
\hline $\begin{array}{l}\text { West et al. } \\
(1968)[2]\end{array}$ & $\begin{array}{c}\text { USA } \\
\text { (California) }\end{array}$ & 1963-1965 & $155 / 1026$ & $15 \%$ \\
\hline $\begin{array}{l}\text { Osawa et al. } \\
\text { (1998)[3] }\end{array}$ & $\begin{array}{c}\text { Japan } \\
\text { (Western } \\
\text { Kanagawa) }\end{array}$ & 1992-1997 & $15 / 188$ & $8 \%$ \\
\hline $\begin{array}{l}\text { Oliva et al. } \\
(2011)[4]\end{array}$ & $\begin{array}{l}\text { Canada } \\
\text { (Quebec) }\end{array}$ & 2002-2006 & $123 / 1260$ & $9.7 \%$ \\
\hline $\begin{array}{l}\text { Tervo et al } \\
(2013)[5]\end{array}$ & Finland & 2008-2009 & $55 / 488$ & $11.3 \%$ \\
\hline
\end{tabular}

$\overline{{ }^{*} \text { Corresponding Author: Hirofumi Aoki, Nagoya University, Nagoya, Japan }}$ Email: hiro.aoki@nagoya-u.jp

www.astesj.com

https://dx.doi.org/10.25046/aj020385
Cardiovascular disease (CVD) and cerebrovascular disease are the most common causes of sudden natural death while driving[6][7]. The effects of cardiovascular disease, such as myocardial infraction, are not immediately but gradual, so that the driver can somehow step on the brake and/or maneuver the vehicle to the side of the road. The pain of cardiac events distracts driver's concentration, and ischemia brought by CVD induces impairment of awareness, recognition, eyesight, physical strength, and others functions.. Syncope is the sudden and transient loss of consciousness. The aftereffect of some serious arrhythmias is syncope that may lead to the lost control of the vehicle. The association of driving and CVD has been investigated for many years [2][8][9]. In Japan, Motozawa et al [6] have reported that among the autopsies results of Transportation Bureau of National Police Agency (Japan), the main cause of death is ischemic heart disease. In European countries, meta-analysis has shown that CVD patients have $23 \%$ higher risk of accident involvement than drivers without CVD [10]. Many other researches also pointed out that CVD drivers have higher risk of accidents than healthy drivers $[11][12][13][14]$. 
Table 2. Percentage of CVD death among intrinsic sudden death at wheel

\begin{tabular}{cccc}
\hline Author & Location & Period & $\begin{array}{c}\text { Intrinsic death caused } \\
\text { by CVD (\%) }\end{array}$ \\
\hline $\begin{array}{c}\text { West et al. } \\
(1968)[2]\end{array}$ & $\begin{array}{c}\text { USA } \\
\text { (California) } \\
\text { USA }\end{array}$ & $1963-1965$ & $94 \%$ \\
$\begin{array}{c}\text { Copeland } \\
(1987)[18]\end{array}$ & $\begin{array}{c}\text { (Florida) } \\
\text { Canada }\end{array}$ & $2002-2006$ & $82 \%$ \\
$\begin{array}{c}\text { Oliva et al. } \\
(2011)[4]\end{array}$ & $\begin{array}{c}\text { (Quebec) } \\
\text { Finland }\end{array}$ & $2008-2009$ & $36.8 \%$ \\
$\begin{array}{c}\text { Tervo et al } \\
(2013)[5]\end{array}$ & (Uusimaa) & $17.8 \%$ \\
\hline
\end{tabular}

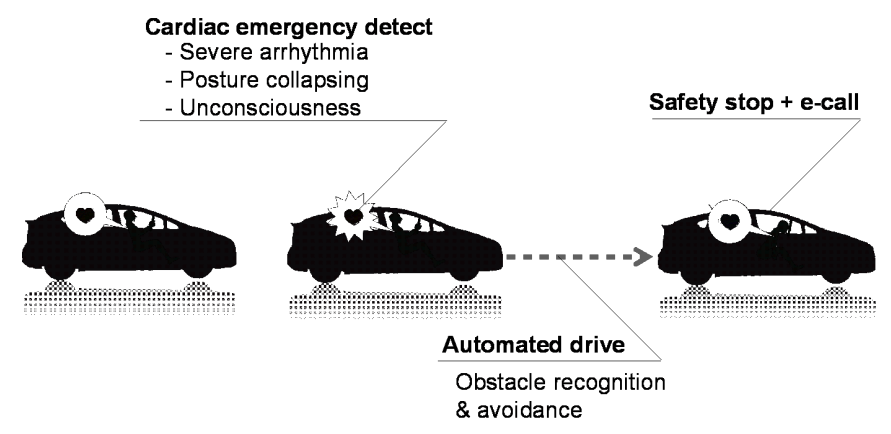

Figure 1. System objective

Various authorities have issued guidelines to detail the criteria for declaring an individual with CVD safe to drive [15][16][17]. Although these methods help decrease the number of death at wheel caused by CVD, drivers still have high potential to get cardiac emergencies behind the wheel, as shown in Table 2. Development of the system that prevents from the CVD-derived accident is essential besides developing the regulations.

This study aims to develop a system that prevents traffic accidents caused by physical disorders. The system detects driver's incapacity by collecting various types of bio-signals and driver's ergonomic factors: electrocardiogram (ECG), photoplethysmogram (PPG), and blood pressure (BP), by using steer-sensors. A driver agent using a camera in front of the driver monitors the driver's posture. The system will take over the maneuver of the vehicle when the driver lost his capacity to drive, and automatically drive to a safety spot by sensing the traffic environment. Figure 1 shows the objective of the research. The following sections describe the concept and the configuration of our first prototype system, The prototype system was designed focusing on cardiac emergencies, and a future prospect of the study.

\section{System configuration}

The system is composed by the following units: Steering wheel-type bio-signal sensor (Steer-sensor), which is for the cardiac emergencies, Driver's ergonomic factors and driver agent assist to confirm situation, and Automated driving system will take over the vehicle to maneuver to safety spot.

\subsection{Bio-signal sensing and cardiac emergency detection}

www.astesj.com

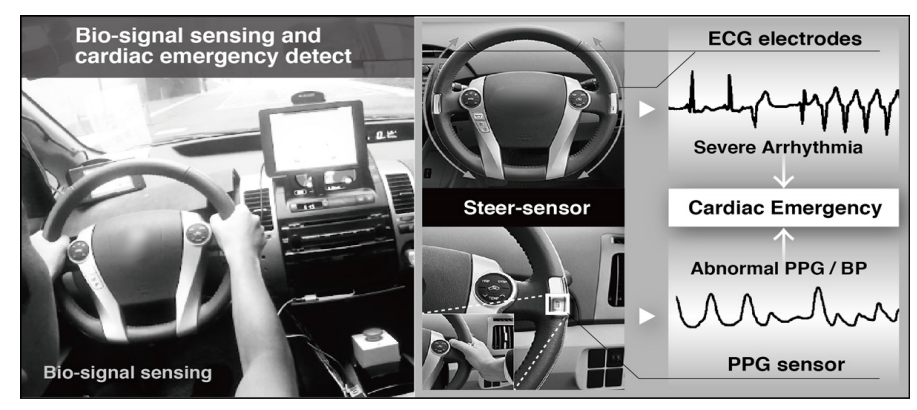

Figure 2. Bio-signal sensing by the steer-sensor and cardiac emergency detection

The collected bio-signals are essential data to detect CVDevent. The electrodes are placed on the outer side of the wheel. ECG and PPG signal are collected by gripping the steering wheel with both hands. Figure 2 shows the position of the both sensors on the wheel. The PPG sensor is located at the place where the base of right thumb touches when a driver grips the wheel in the usual manner. BP is estimated from the pulse transit time (PTT) measured by the ECG and PPG. Further detail is referred to [19][20].

Combining the characteristics of following patterns: 1) tachycardia or bradycardia, 2) abnormality of QRS complex, 3) irregularity of R-R or P-Q intervals, 4) abnormality of BP; the type of cardiac emergency is estimated. Depending on the type of arrhythmias, the normal heart rate will be affected and heart rate might be faster or slower or erratic. These abnormal states of heart rate will affect the control capacity of the driver. When the lifethreatening arrhythmias such as ventricular tachycardia (VT), ventricular fibrillation (VF), Torsade de Pointes, or cardiac arrest with the abnormal PPG and BP are detected, the system triggers the emergency signal to the later unit.

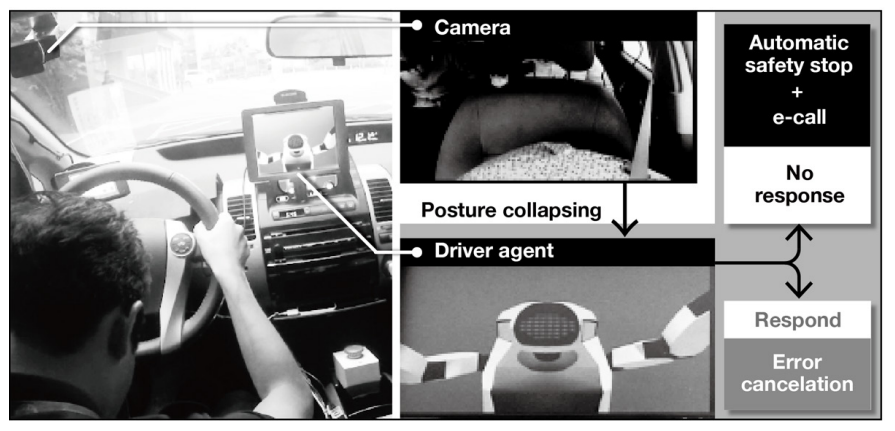

Figure 3. Posture collapsing detection

\subsection{Driver's ergonomic factor and driver agent assist}

When the system detects an abnormality in driver's bio-state sent from the prior unit, the driver's posture is captured by the driver-monitor camera settled in front of the driver (Figure 3). Some arrhythmias cause pain and/or numb in the chest and shoulder, some make driver feel dizzy or faint. In most of the cases, drivers with serious trouble feel uncomfortable in their chest first and then eventually lose their normal driving posture. A driver agent is installed inside the vehicle to give instruction and alerts while driving. 


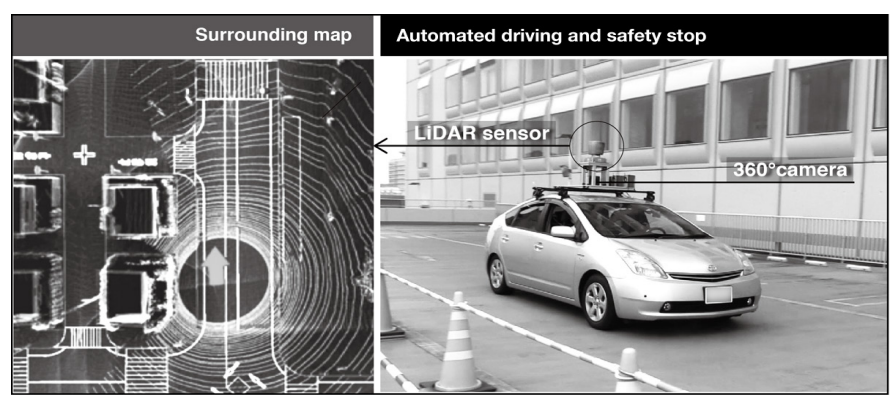

Figure 4. Automated driving and safety stop

By using driving instruction model, the driver agent handles cameras data and driving records to monitor driver's driving performance and give instructions if needed to improve driving behavior. If the driver's abnormal posture is detected, the driver agent alerts the driver. The alerting is settled in order to avoid the misdetection of the arrhythmia and posture collapsing. Autonomous drive is activated by the absence of response to the alert for certain duration, and then emergency call (e-call) is taken. Further detail of the driver agent is referred to [21].

\subsection{Automated driving system}

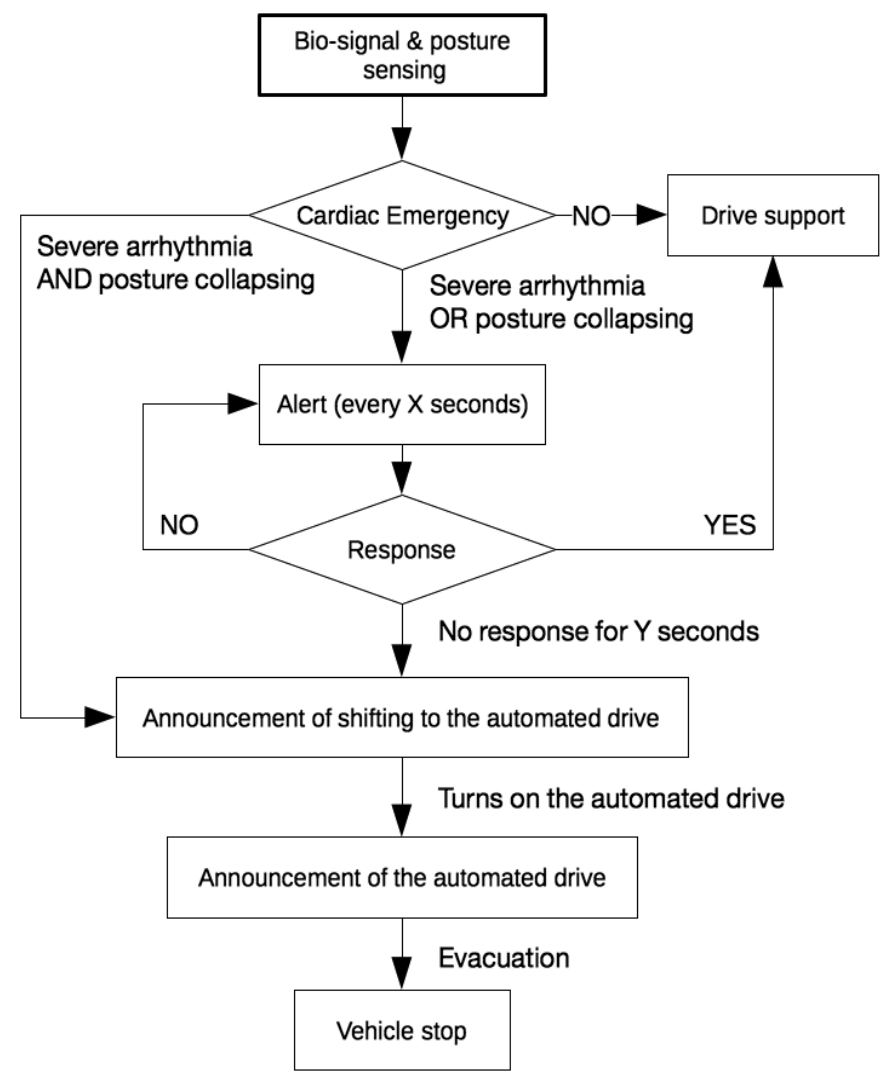

Figure 5. Decision-making procedure of the manual-to automated shift

Various sub-systems in the automated driving system enable the vehicle capture to the surrounding environment: by a LiDAR sensor (HDL-64E, Velodyne LiDAR, Inc.), 360 degrees camera (Ladybug 5, Point Grey Research, Inc.), Grasshoper 3 cameras and Javad RTK sensors receive global positioning information from satellites as shown in the Figure 4. By combining Velodyne LiDAR sensor and Ladybug 5, the system obtains 3D point-cloud data for localization and mapping, and is also used to measure the distance to surrounding objects and moving objects. The Grasshoper can be used to detect traffic lights. The system enables to estimate the position with the precision of $0.1 \mathrm{~m}$. This configuration allows the vehicle to drive and avoid obstacles on the road after taking control from the driver. Further detail is referred to [22].

When the driver's critical state is confirmed and trigger signal is sent from prior units, the automated driving mode is activated. The system recognizes the surrounding of the vehicle and automatically finds a safety spot to park the vehicle. Figure 5 shows the decision-making procedure of the manual-to-automated shift.

\section{Demonstration}

The prototype of the system has been demonstrated at TOC Ariake, Tokyo, Japan in 28th August 2015. A well-prepared scenario was set to demonstrate the working prototype: The driver is driving with normal state then the abnormal state is injected to the system to simulate the critical situation.

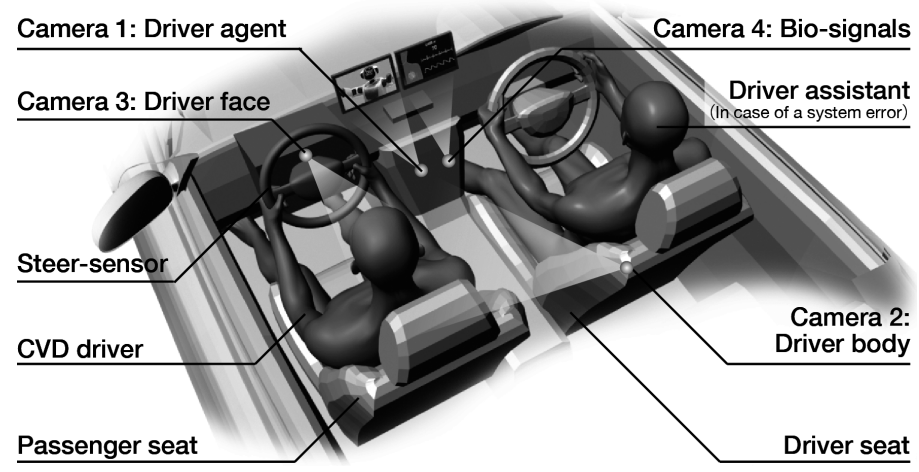

Figure 5. Interior layout of the demonstration

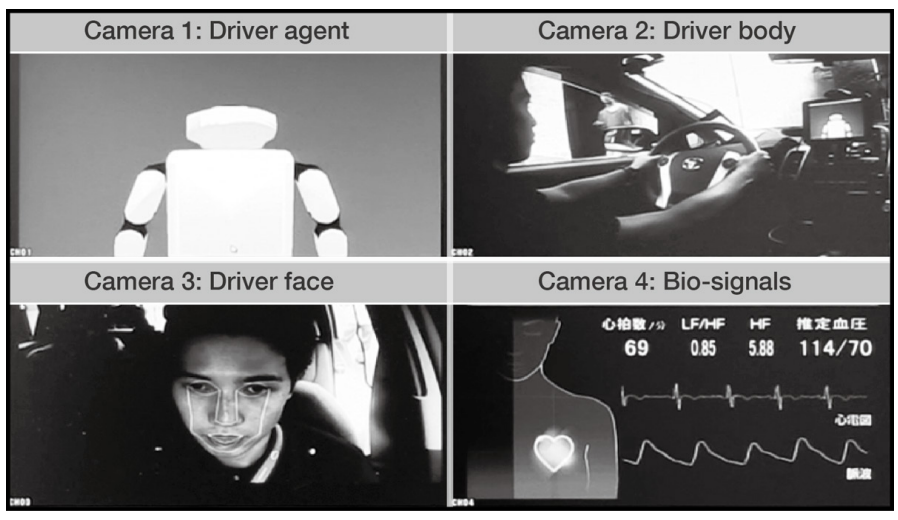

Figure 6. Captured images by the cameras at the demonstration 


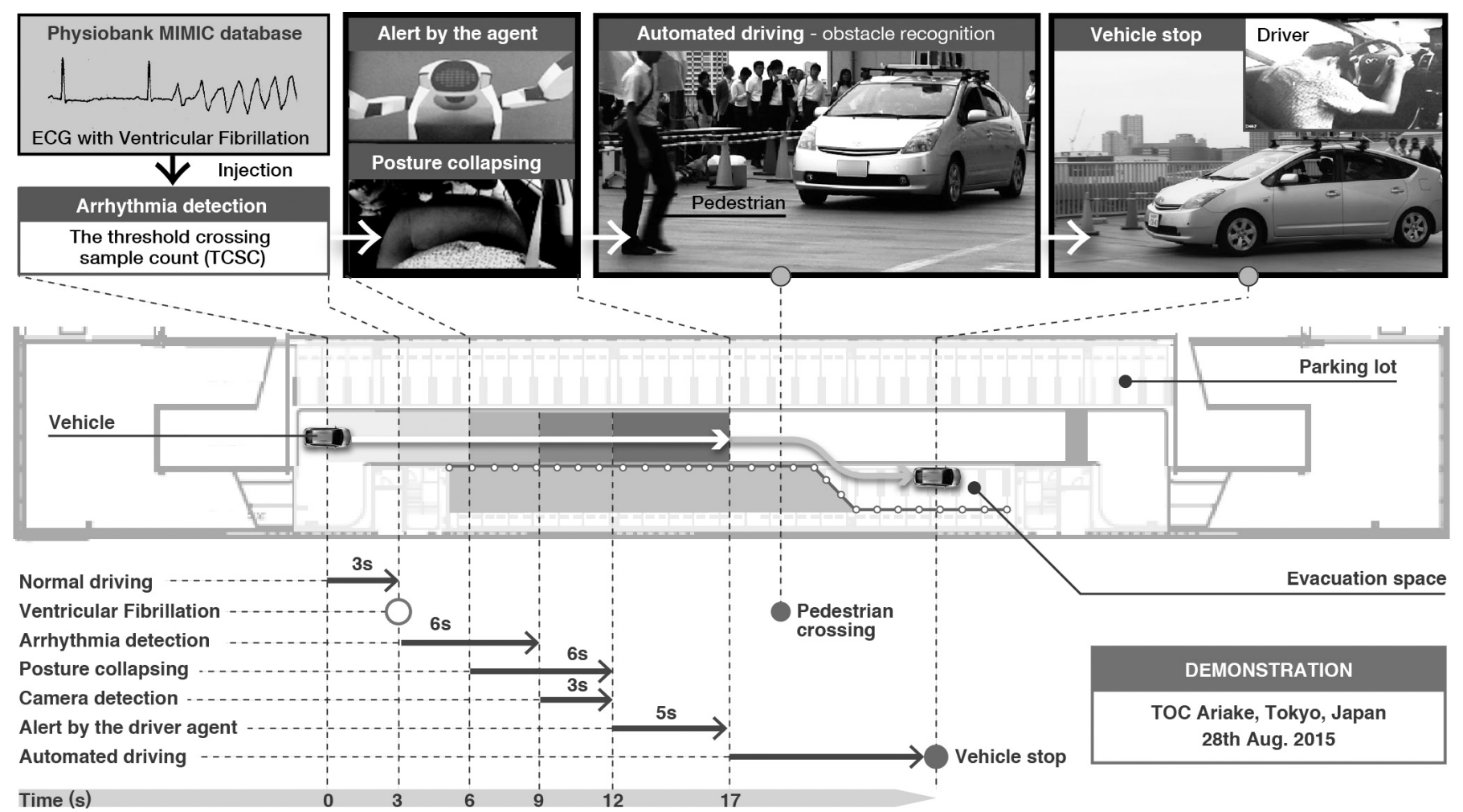

Figure 7. Scenario of the demonstration conducted at TOC Ariake, Tokyo, Japan in $28^{\text {th }}$ August 2015

Normal ECG data was collected by the sensor, then the ECG with ventricular fibrillation (VF), obtained from PhysioBank MIMIC database [23], was used for simulation of the emergency situation.

The threshold crossing sample count (TCSC) [24] was implemented for the VF detection. Considering the safeness of the demonstration, the steer-sensor and the driver-monitoring camera were settled on the passenger seat as shown on the Figure 5. The assistant driver on the driver seat will take countermeasures in case of system errors during the transition of manual-to-autonomous driving and while automated driving. Four cameras were settled to monitor the conditions of inside the vehicle: two for capturing driver's face and posture, one for driver agent and one for driver's bio-signals.

The captured images (Figure 6) were sent to the monitor placed in front of the audience wirelessly. The scenario of the demonstration is illustrated in the Figure 8. It started from normal driving with the speed of $20 \mathrm{~km} / \mathrm{h}$, it took about 3 seconds to let the vehicle reached the designated velocity and all systems worked in normal state. Soon after the simulated VF was injected, the arrhythmia detection and cameras worked simultaneously to catch the emergency situation. The posture collapsing of the driver were detected by the face recognition. In the meantime, the agent gave an alert to the driver to confirm the situation. Then the system automatically turned on the automated driving when it confirms the driver's critical state. In the scenario, a pedestrian crossed in front of the vehicle while the system turned into the automated mode. It successfully recognized the pedestrian and stopped while he was crossing the road. Soon after it confirmed no obstacles ahead; it drove to the safety spot (Evacuation space on the Figure 8) and stopped the vehicle. All the procedures after the VF injection were done automatically.

\section{Discussion}

European automobile manufacturers have developed the related system in recent years [25]. Their system prevents frontal crash and lane departures by an adaptive cruise control and a lanekeep assist when a driver lost his capacity to drive by a physical disorder. It also alerts the driver by an indicator and warning brakes, and evacuates the vehicle with hazard lumps when there is no response from the driver. The similar demonstration has shown at the 22nd ITS world congress, Bordeaux, France, in October 2015 [26]. Driver's incapacity was detected by a camera and automatically stopped the vehicle on the shoulder of a road at the demonstration. Although the related system is well designed for the countermeasures for incapacitated drivers, the future studies require detection methodologies of the driver's incapacity at earlier stage. Even a few seconds of beforehand detection decreases the risk of crash. Since the bio-signals indicate the abnormality of the driver before he/she gets incapacity, our system has a potential for minimizing the crash risk. The prototype of the system using biosignal detection was successfully demonstrated its function at the prepared scenario.

The demonstration, however, also revealed its limitations and problems. Tests with conventional ECG sensor has showed that the driving condition actively adds noise to the signal. Moving artifacts due to body motion were sometimes detected as severe arrhythmias, resulting in misdetections. Since the steer-sensor generates more noises on the ECG than conventional sensors, that uses adhesive electrodes, the waveform of the PQRST complex easily gets distorted. Therefore, it requires additional methodologies on the conventional arrhythmia detection. Moreover, gripping the wheel by both hands all the time is not practical in the real driving scenes, so that it requires 


\section{T. T. Nguyen et al. / Advances in Science, Technology and Engineering Systems Journal Vol. 2, No. 3, 669-673 (2017)}

accompanying sensors such as capacitive ECG sensor or wearable PPG sensor to compensate the signal distortions or the signal losses or combine with other technologies to compensate signal when the driver drives with one hand. As shown in the Figure 7, the duration of uncontrolled vehicle is 14 seconds and the initial velocity when the arrhythmia started was $20 \mathrm{~km} / \mathrm{h}(5.6 \mathrm{~m} / \mathrm{s})$. Thus, the distance the vehicle kept moving is 78 meters. In unconsciousness state, the driver can step on the gas pedal or steer the vehicle out of the lane. Both of above situations will eventually lead to accident. It is needed to shorten the detection time of both arrhythmia and posture collapse. Normally, if the driver feels any discomfort while driving he/she will apply brake and slow down. But others might suffer more serious situation and collapse before the accident happen. In that case, it is important to develop methodology to predict arrhythmia before it happen. In addition, it is not always safe to stop the vehicle at a certain spot. Further investigation of coping behavior in the emergency situation is essential for the development.

\section{Conclusion}

The study demonstrated the concept of the automated safety vehicle stop system for cardiac emergencies. The prototype system has shown potential benefits to both patients and normal healthy people. But the system contains many limitations requiring their solutions: the sensor quality and investigation of emergency management on the various driving situations. Moreover, detecting driving incapacity requires not only bio-signals but also other risk factors such as driving performance, driver's state, driver's medical history etc. Currently, we are focusing on the effects of the driving situations, the effects of physical stress and cognitive stress on CVD patients and healthy subjects. These topics are dedicated to our further studies.

\section{Conflict of Interest}

The authors declare no conflict of interest.

\section{Acknowledgment}

The authors would like to acknowledge to Sadayoshi Tateishi, Prof. Nishiyama Kiyohisa in Nagoya University, Minoru Makiguchi in Toyota Motor Corporation, and Tsuyoshi Nakagawa with Denso. This research is in part supported by the Center of Innovation Program (Nagoya COI) from Japan Science and Technology Agency and Toyota Motor Corporation.

\section{References}

[1] M. T. Schultheis, J. DeLuca, and D. Chute, Handbook for the assessment of driving capacity. Academic Press, 2011.

[2] I. West, G. L. Nielsen, A. E. Gilmore, and J. R. Ryan, "Natural Death at the Wheel," JAMA J. Am. Med. Assoc., vol. 205, no. 5, p. 266, Jul. 1968.

[3] M. Osawa et al., "Sudden natural death in driving: case studies in the western area of Kanagawa.," Nihon Hoigaku Zasshi, vol. 52, no. 5, pp. 315-8, Oct. 1998.

[4] A. Oliva et al., "Autopsy investigation and Bayesian approach to coronary artery disease in victims of motor-vehicle accidents," Atherosclerosis, vol. 218, no. 1, pp. 28-32, 2011.

[5] T. Tervo et al., "Sudden Death at the Wheel Due to a Disease Attack Sudden Death at the Wheel Due to a Disease Attack," Traffic Inj. Prev., vol. 14, no. 14, pp. 138-144, 2013.

[6] Y. Motozawa, J. M. Hitosugi, and S. Tokudome, "Analysis of Sudden natural deaths while driving with forensic autopsy findings."

www.astesj.com
[7] P. Schmidt, K. Haarhoff, and W. Bonte, "Sudden natural death at the wheel A particular problem of the elderly?," Forensic Sci. Int., vol. 48, no. 2, pp. 155-162, 1990.

[8] S. P. Baker and W. U. Spitz, "An evaluation of the hazard created by natural death at the wheel," N. Engl. J. Med., vol. 283, no. 8, pp. 405-409, 1970.

[9] T. Tervo, E. Räty, P. Sulander, J. M. Holopainen, T. Jaakkola, and K. Parkkari, "Sudden Death at the Wheel Due to a Disease Attack," Traffic Inj. Prev., vol. 14, no. 2, pp. 138-144, Jan. 2013.

[10] C. N. O. Gma, T. Vaa, T. Economics, J. Alvarez, and B. Hockey, Impairments, Diseases, Age and their Relative Risks of Accident Involvement: results from meta-analysis, IMMORTAL, no. August. 2003.

[11] J. A. Waller, "Chronic medical conditions and traffic safety: review of the California experience," N. Engl. J. Med., vol. 273, no. 26, pp. 1413-1420, 1965.

[12] J. A. Waller, "Cardiovascular disease, aging, and traffic accidents," J. Chronic Dis., vol. 20, no. 8, pp. 615-620, 1967.

[13] a. Crancer and L. McMurray, "Accident and Violation Rates of Washington's Medically Restricted Drivers," JAMA J. Am. Med. Assoc., vol. 205, no. 5, pp. 272-276, 1968.

[14] Y. Lerman, M. Matar, B. Lavie, and Y. L. Danon, "Effect of Valvular Heart Diseases, Migraine Headaches, and Perianal Diseases on the Risk of Involvement in Motor Vehicle Crashes," J. Trauma Inj. Infect. Crit. Care, vol. 39, no. 6, pp. 1058-1062, 1995.

[15] D. G. K. Theodoros A. Zografos, "Review Article Guidelines and Regulations for Driving in Heart Disease," Hell. J. Cardiol., vol. 51, pp. 226-234, 2010.

[16] A. E. Epstein et al., "Personal and Public Safety Issues Related to Arrhythmias That May Affect Consciousness: Implications for Regulation and Physician Recommendations," Circulation, vol. 94, pp. 1147-1166, 1996.

[17] M. C. Petch, "Driving and heart disease, Prepared on behalf of the Task Force by M. C. Petch," Eur. Heart J., vol. 19, no. 8, pp. 1165-1177, Aug. 1998.

[18] A. R. Copeland, "Sudden Natural Death 'At the Wheel'-Revisited," Med. Sci. Law, vol. 27, no. 2, pp. 106-113, Apr. 1987.

[19] K. Futatsuyama, N. Mitsumoto, T. Kawachi, and T. Nakagawa, "Noise Robust Optical Sensor for Driver's Vital Signs," in SAE Technical Paper, 2011, p. No. 2011-01-1024

[20] M. Osaka, H. Murata, Y. Fuwamoto, S. Nanba, K. Sakai, and T. Katoh, "Application of heart rate variability analysis to electrocardiogram recorded outside the driver's awareness from an automobile steering wheel," Circ. J., vol. 72, no. 11, pp. 1867-1873, 2008.

[21] T. Tanaka et al., "Driver Agent for Supporting Elderly Driver," in HumanAgent Interaction Symposium 2015, 2015, pp. 115-118.

[22] S. Kato, E. Takeuchi, Y. Ishiguro, Y. Ninomiya, K. Takeda, and T. Hamada, "An Open Approach to Autonomous Vehicles," IEEE Micro, vol. 35, no. 6, pp. 60-68, 2015.

[23] G. B. Moody and R. G. Mark, "A database to support development and evaluation of intelligent intensive care monitoring," Comput. Cardiol., vol. 23, pp. 657-660, 1996.

[24] M. A. Arafat, A. W. Chowdhury, and M. K. Hasan, "A simple time domain algorithm for the detection of ventricular fibrillation in electrocardiogram," Signal, Image Video Process., vol. 5, no. 1, pp. 1-10, 2011.

[25] Volkswagen, "Emergency Assist," 2016. .

[26] AISIN SEIKI Co.Ltd., "Aisin Group to exhibit at 22nd ITS World Congress Bordeaux 2015,” 2015. . 